\title{
Médiévales
}

Langues, Textes, Histoire

51 | automne 2006

L'Occident sur ses marges ( $\left.\mathrm{V}\right|^{\mathrm{e}}-\mathrm{XI}^{\mathrm{e}}$ siècles)

\section{Céline Martin, La Géographie du pouvoir dans}

l'Espagne visigothique

Lille, Presses Universitaires du Septentrion (collection Histoire et Civilisations), 2003, 407 p.

\section{Geneviève Bührer-Thierry}

\section{(2) OpenEdition}

Journals

Édition électronique

URL : https://journals.openedition.org/medievales/1438

DOI : 10.4000/medievales. 1438

ISSN : $1777-5892$

Éditeur

Presses universitaires de Vincennes

Édition imprimée

Date de publication : 1 décembre 2006

Pagination : 167-168

ISBN : 978-2-84292-193-4

ISSN : 0751-2708

Référence électronique

Geneviève Bührer-Thierry, "Céline Martin, La Géographie du pouvoir dans I'Espagne visigothique »,

Médiévales [En ligne], 51 | automne 2006, mis en ligne le 12 mars 2007, consulté le 24 avril 2022. URL:

http://journals.openedition.org/medievales/1438; DOI : https://doi.org/10.4000/medievales. 1438

Ce document a été généré automatiquement le 24 avril 2022.

Tous droits réservés 


\title{
Céline Martin, La Géographie du pouvoir dans l'Espagne visigothique
}

\author{
Lille, Presses Universitaires du Septentrion (collection Histoire et
} Civilisations), 2003, 407 p.

\section{Geneviève Bührer-Thierry}

1 Le problème de la transition entre le monde romain antique et le monde médiéval «barbare » ne se pose nulle part avec autant d'acuité que dans l'Espagne visigothique : confrontant les traditions historiographiques qui voient dans le royaume des Visigoths tantôt la rupture des traditions romaines d'unité du pouvoir, tantôt une continuité particulièrement visible dans les modèles culturels et dans le droit, Céline Martin s'attache à réfléchir sur la question qui divise les historiens, celle des lieux de pouvoirs. $C^{\prime}$ est en effet la nature des relations entretenues par les pôles locaux et la structure englobante qui est à la racine du débat qui oppose les tenants d'une rupture historique aux défenseurs de la survie de Rome après le $v^{e}$ siècle. $C$. Martin s'assigne donc comme but de décrire l'articulation du double niveau de pouvoir devenu traditionnel à la fin de l'Antiquité, en prenant en considération à la fois la géographie administrative et la géographie mentale, la formalisation juridique du contrôle de l'espace et sa force symbolique, en mettant en œuvre l'ensemble des sources disponibles qui ont la particularité d'être presque exclusivement des écrits théoriques.

2 C. Martin commence sa réflexion sur les lieux de pouvoirs par une première partie qui traite de la maîtrise de l'espace (p.31-141). Elle montre d'une part comment la péninsule évolue vers une hiérarchisation des noyaux de peuplement, chaque pôle représentant un élement-clef du maillage du territoire et possédant une réelle zone d'influence, d'autre part l'existence d'un réel sentiment d'unité au sein d'un royaume qui n'est pas perçu comme un conglomérat de régions hétérogènes, à l'exception toutefois de la Narbonnaise, les Pyrénées constituant en fait la seule ligne de fracture importante. Localement, le pouvoir est dans les mains d'hommes particuliers, puissants laïcs, saints hommes ou encore évêques, dont la caractéristique commune est d'apporter une protection à la population, sans rien devoir au pouvoir central : faut-il 
pour autant les considérer comme autant de ferments de divisions à l'intérieur du royaume?

3 Pour répondre à cette question, C. Martin traite de la centralité du pouvoir (p. 143-277) dont elle perçoit essentiellement un renforcement continue depuis le vi ${ }^{e}$ siècle, battant largement en brèche les théories attribuant la chute du royaume visigothique à l'affaiblissement de ses structures étatiques. Cette centralisation caractérise particulièrement bien le milieu du viI ${ }^{\mathrm{e}}$ siècle, marqué par des réformes administratives, monétaires et judiciaires et surtout par la promotion de Tolède, désignée désormais comme urbs regia, civitas regia dans la plus pure tradition impériale. Véritable capitale, Tolède est le siège permanent des institutions centrales d'un État, la tête d'un organisme politique, et il existe une différence de nature et non pas seulement de degré entre la capitale et les autres villes du royaume en raison du rôle de direction politique qui lui a été confié. Mais $\mathrm{C}$. Martin montre aussi que cette centralisation ne se fait pas contre les élites locales, mais emporte au contraire l'adhésion des grands laïques et ecclésiastiques ce qui s'explique par la capacité du royaume de Tolède à se présenter comme un tout cohérent.

4 C'est l'étude des fondements de cette cohésion qui constitue la dernière partie de l'ouvrage (p. 279-370). C. Martin développe l'idée de «frontières fondatrices» du royaume visigothique: les frontières demeurent fermées non pas pour se prémunir d'éventuelles attaques, mais pour définir une identité spécifique. Le royaume est fermé sur lui-même par des frontières considérées comme naturelles et immuables et il se construit de l'intérieur autour de sa capitale éloignée des confins, c'est un « royaume sanctuaire ». L'espace cependant n'est jamais appréhendé de manière concrète et mathématique, mais selon une perception globale généralisante: il fait l'objet d'une lecture symbolique, voire spirituelle, qui conduit à voir dans le royaume des Visigoths une construction mystique, la politique y étant davantage conçue comme un instrument du Salut que comme un mode de gestion de la vie en commun. Dans ce cadre, c'est le roi qui est la clef de voûte de l'édifice, investi d'une mission qui lui commande de reproduire sur terre l'ordre divin et de mener le peuple qui lui a été confié vers la purification nécessaire à la fin des Temps. Ce souci d'ordre théologique plus que politique, sous-tendu par des perspectives eschatologiques qui se développent à partir du milieu du viI ${ }^{\mathrm{e}}$ siècle, a pour conséquence dramatique la conversion forcée puis la persécution des juifs d'Espagne, dont C. Martin montre qu'elles ne doivent rien au modèle byzantin (elles les précèdent d'une vingtaine d'années) et qu'elles ne sont pas non plus liées à des raisons économiques, mais se rapportent à la mission de conversion assignée au monarque.

Dans un tel système, la relation du roi à chaque sujet ne connaît aucune médiatisation : elle est formalisée par le serment de fidélité, un lien spécifique de caractère public qui ne prolonge pas les liens personnels entretenus avec les puissants locaux mais renvoie à une instance transcendant le souverain lui-même, c'est-à-dire à l'État. L'existence de l'État, sous l'appellation gens et patria, apparaît donc indéniable : mode d'organisation politique nouveau dont la fin ultime est métaphysique, il est essentiellement lié à la dimension sacrale du pouvoir terrestre.

6 Le royaume des Visigoths formait donc bien un État, sans nul doute descendant de Rome, mais un État d'un type particulier, dont le personnel, l'action et l'idéologie relevaient au moins autant de la sphère religieuse que politique. En cela, on reconnaîtra les prémisses de nombreux «États » du Moyen Âge, et on ne pourra que conseiller la 
lecture de ce livre à tous ceux qui s'intéressent à l'histoire des représentations et des institutions politiques médiévales, mais aussi à tous ceux qui mènent une réflexion sur le rôle de l'espace dans la construction du pouvoir. 